\section{Fruit Quality of Satsuma Mandarin Grown on the Northern Coast of the Gulf of Mexico}

\author{
R.C. Ebel, ${ }^{1}$ W.A. Dozier,${ }^{3}$ B. Hockema, ${ }^{4}$ F.M. Woods,${ }^{5}$ R. Thomas, ${ }^{6}$ and \\ B.S. Wilkins ${ }^{7}$ \\ Department of Horticulture, 101 Funchess Hall, Auburn University, AL 36849
}

\author{
M. Nesbitt ${ }^{2}$ and R. McDaniel ${ }^{8}$ \\ Alabama Agricultural Experiment Station, Gulf Coast Research and Extension \\ Center, 8300 State Highway 104, Fairhope, AL 36532
}

Additional index words. Citrus unshiu, fruit weight, peel color, soluble solids, titratable acidity

\begin{abstract}
This study was conducted to determine fruit quality of Satsuma mandarin Citrus unshiu, Marc. 'Owari' grown on the northern coast of the Gulf of Mexico. Soluble solids increased linearly and titratable acidity decreased quadratically during October and November for the four sampling years. There was no significant interaction between sampling date and year. There was a significant year effect for titratable acidity, but not soluble solids or their ratio. A 10:1 soluble solids to titratable acidity ratio was observed on 10 Nov. Variation in fruit weight corresponded with cropload. Fruit weight increased during the sampling period due to an increase in fruit length since there was no change in width. Peel color was yellow-orange by 10 Nov., with many fruit still exhibiting patches of green color. Because of some green color present in the peel, the fruit would have to be degreened for successful marketing in U.S. retail chain stores.
\end{abstract}

Satsuma mandarins are small citrus fruit closely related to other mandarins such as tangerines and clementines. They are sweet, easily peeled by hand and seedless. Satsuma mandarins budded onto Poncirus trifoliata (L.) Raf. rootstock are the most cold-hardy of all commercial citrus (Yelenosky, 1985), which allows their production in the northernmost areas of the citrus region in the southeastern U.S. Satsuma mandarins were a major industry along the northern fringe of the Gulf Coast in the early 1900s, with fruit shipped to 45 cities throughout the U.S. and Canada, and England (Rucker, 1996; Vosbury, 1923; Winburg, 1948). Freezing weather destroyed the early industry and later attempts to reestablish it (Rucker, 1996; Winburg, 1948). Due to modern freeze protection measures such as microsprinkler irrigation (Edling et al., 1992; Nesbitt et al., 2000), potentially cold hardy Satsuma mandarin selections (Zhang et al., 2002), and the absence of devastating freezes since 1989, there has developed a strong effort to revive a Satsuma mandarin industry in this region.

Internal fruit quality, which largely constitutes flavor, is mainly a function of sugars

Received for publication 26 June 2003. Accepted 4 Dec. 2003. This project was funded in part by USDA Special Research Grant OEP \#2001-03124, a grant from the USDA-Federal State Marketing Improvement Program, and the Alabama Agricultural Experiment Station.

${ }^{1}$ Associate professor. Corresponding author; e-mail rcebel@acesag.auburn.edu.

${ }^{2}$ Research horticulturist.

${ }^{3}$ Professor.

${ }^{4}$ Research associate II.

${ }^{5}$ Associate professor.

${ }^{6}$ Graduate research assistant.

${ }^{7}$ Field research associate III

${ }^{8}$ Superintendent. and acids. Sugar content increases and acid content decreases during development and maturation (Halpern and Zur, 1988; Monselise, 1987); however, many abiotic factors affect the rate and absolute amount including air and soil temperatures (Kurihara, 1969; Marsh et al., 1999; McAneney et al., 1995; Richardson et al., 1997) and cropload (Harty and Sutton, 1994; Zheping et al., 2001). Peel color is also affected by temperature, but in a manner that does not correlate with changes in internal quality (Spiegel-Roy and Goldschmidt, 1996). Thus, fruit from different regions can have contrasting internal and external quality. Determining fruit quality in any particular region, coupled with consumer preference surveys (Campbell, 2003), will aid optimizing harvest and postharvest handling methods for market development.

Satsuma mandarins are a non-climacteric fruit that ripen slowly (Aharoni, 1968; Eaks, 1970; Goldschmidt et al., 1993). Once mature, quality declines gradually allowing fruit to be stored on the tree until markets are available (Spiegel-Roy and Goldschmidt, 1996). There has been a tendency by growers to harvest too early when fruit have less than optimum or even poor quality, which reduces market demand. To protect their markets, countries and states such as Louisiana legally enforce a minimum internal quality, such as a 10:1 soluble solids to titratable acidity ratio, before fruit can be sold on the market (Roy Constantin, personal communication; Spiegel-Roy and Goldschmidt, 1996). Adopting the same harvest standard would facilitate cooperation in development of a region-wide industry.

This study was conducted to determine internal and external fruit quality during development and maturation of Satsuma mandarins grown in southern Alabama. Results have been discussed with respect to the timing of the optimum harvest window starting when the soluble solids to acid ratio reached 10:1, the external attributes when the minimum internal standard was reached, and postharvest handling methods that would need to be conducted to meet requirements of retail chain stores as determined in a recently conducted consumer preference survey (Campbell, 2003).

\section{Materials and Methods}

Fruit for this study were harvested from mature Satsuma mandarin trees (Citrus unshiu, Marc. 'Owari') budded onto Poncirus trifoliata (L.) Raf. 'Rubidoux' rootstock. 'Owari' is a late-maturing cultivar of Satsuma mandarin. Trees were planted in a $4.6 \times 7.6$-m planting in 1990 at the Alabama Agricultural Experiment Station Gulf Coast Research and Extension Center at Fairhope located $1.6 \mathrm{~km}$ east of Mobile Bay, which was $30^{\circ} 33^{\prime} \mathrm{N}$ and $87^{\circ} 53^{\prime} \mathrm{W}$ and $7 \mathrm{~m}$ elevation. Fertilization, irrigation, and insect, disease, and weed control were according to current commercial recommendations. Management of commercial groves in this region does not currently include crop thinning in heavy bearing years and therefore we did not attempt to thin the crop in this study.

In 1998 and 1999, five fruit were randomly selected from each of the four trees every 2 to $7 \mathrm{~d}$ in October and November. Trees were randomly selected before the first sampling date, and then the same trees were sampled throughout the year. Fruit were cut in half and juice from both halves was manually expressed through 0.8-mm mesh screen. Three drops of juice were placed on a hand-held, temperaturecompensated refractometer (model 300010; Sper Scientific, Scottsdale, Ariz.) to determine soluble solids content. Titratable acidity was determined from $10 \mathrm{~mL}$ of juice by adding 5 drops of $1 \%$ phenolphthalein solution in $50 \%$ isopropyl alcohol, and stirring while adding 0.1 $\mathrm{N} \mathrm{NaOH}$ until the solution color changed from yellow-orange to pink ( $\mathrm{pH}$ endpoint $=8.2$ ).

In 2001 and 2002, five fruit were harvested weekly from each of the four cardinal sides of five trees beginning in the first week of October. Trees were randomly selected at the beginning of the study and then the same four trees were sampled throughout the study. All fruit were weighed, and their length and diameter were measured. Peel color was determined on two sides of each fruit using an electronic spectrophotometer to determine hue angle and chroma (chromameter model CM-2002; Minolta Camera Co., Japan). Hue angle is a measure of color from green to yellow to orange, and chroma is the intensity of hue angle color from near white to pure color (McGuire, 1992; Voss, 1992).

Each fruit was cut in half and squeezed using an electric hand juicer (model HJ28; Black and Decker, Townsend, Md.). Expressed juice from all five fruit from each quandrant of each tree was combined. After mixing and filtering through cheese cloth, $1 \mathrm{~mL}$ juice aliquot was removed to measure soluble solids using a temperature-compensated refractometer (model 


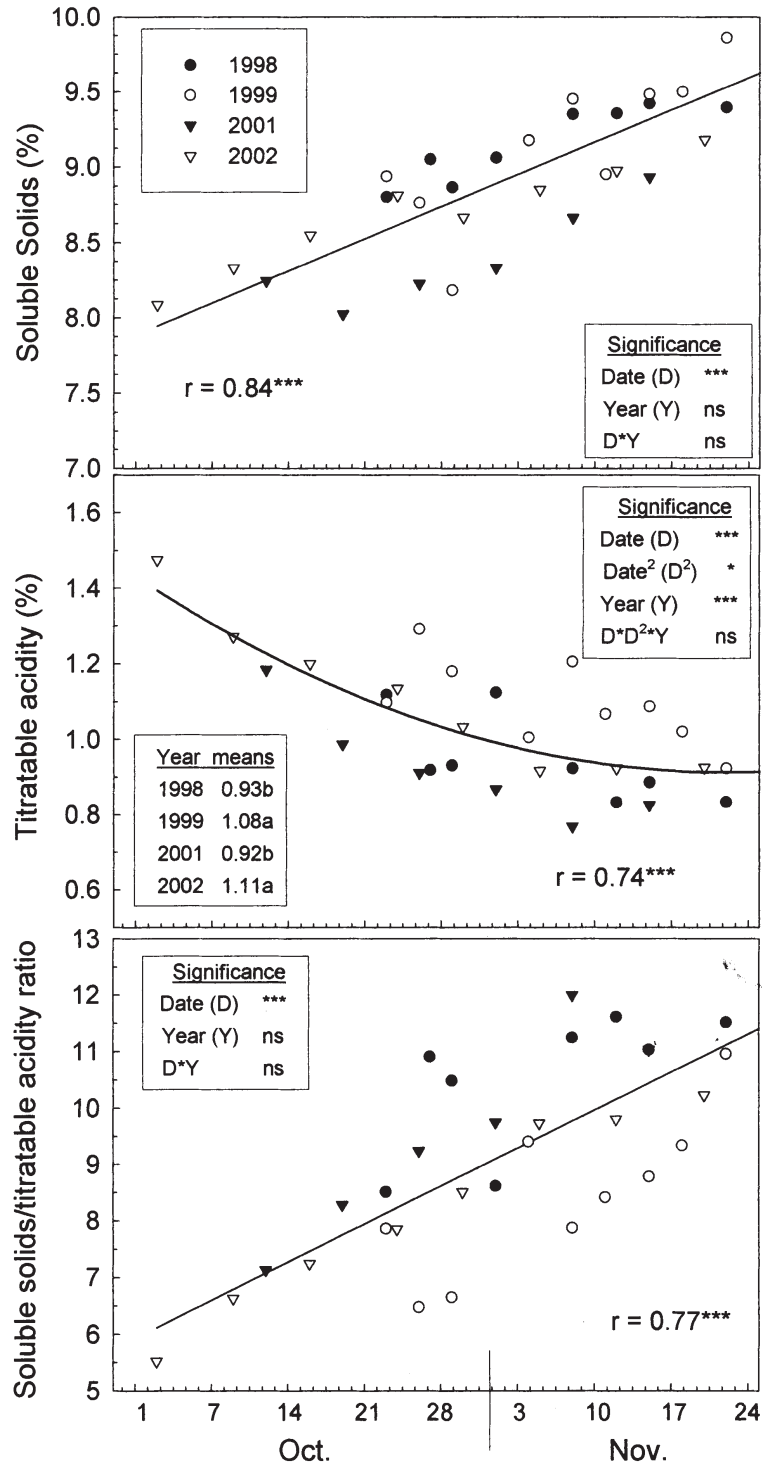

Fig. 1. Development of fruit soluble solids and titratable acidity during maturation. The key 10:1 ratio of soluble solids to titratable acidity, which indicates the earliest date acceptable for harvest, occurred on 10 Nov. The inset boxes indicate level of significance using Analysis of Variance. ${ }^{*, * * * * * *}$ Significance levels in the analysis of variance and correlation coefficients were determined at $P \leq 0.05,0.01$, or 0.001 , respectively. The inset box in the lower left of the titratable acidity graph shows average differences among years.

10494; Leica Microsystems Inc., Buffalo, N.Y.). Titratable acidity was determined by titrating to a $\mathrm{pH}$ of 8.1 with $0.1 \mathrm{~N} \mathrm{KOH} \mathrm{using} \mathrm{an}$ automated titrimeter (Metrohm Titrino model 751 GPD and Metrohm Sample Changer; Metrohm Corp., Herisau, Switzerland) and computer software (Titrino Worcell 4.4 Software, Brinkmann Corp., Westbury, N.Y.).

Yield was determined for 20 to 138 trees every year after planting. Multiple harvests were conducted throughout the autumn and early winter with fruit chosen based on advancement of peel color.

Data were analyzed as a completely randomized design using the General Linear Model procedure of the Statistical Analysis
System (SAS Institute, 1985). The independent variable "Date" was included in the model as a continuous variable, "Year" was included in the model as a discreet variable, and their interaction was tested. In the absence of significant interactions, main effect means were separated using Duncan's multiple range test $(P \leq 0.05)$. Regressions were determined using the Regression Procedure of the Statistical Analysis System (SAS Institute, 1985).

\section{Results and Discussion}

Soluble solids increased linearly during the sampling period but showed no significant interaction between date and year (Fig. 1). Titratable acidity decreased quadratically during the sampling period. There was no significant interaction between date and year; however, titratable acidity differed among the four years with 1999 and 2002 being higher than in 1998 and 2001. The ratio of soluble solids to titratable acidity increased linearly. There was no significant interaction between date and year in the ratio of soluble solids to titratable acidity, nor was there a difference in means among years. The soluble solids to titratable acidity ratio reached 10:1 on 10 Nov.

There was considerable variation in the soluble solids and titratable acidity data within and among years. There are many factors that affected the development of fruit quality. Temperature was one of the most important factors (Kurihara, 1969; Marsh et al., 1999; McAneney et al., 1995; Richardson et al., 1997), and the Southeast has been characterized by a highly variable climate. Air temperature during the bloom period has a strong impact on accumulation of soluble solids in fruit (Marsh et al., 1999; Richardson et al., 1997). Average daily air temperature during bloom in April was $18.7^{\circ} \mathrm{C}$ in $1998,21.7^{\circ} \mathrm{C}$ in 1999 , $20.4{ }^{\circ} \mathrm{C}$ in 2001 and $21.4{ }^{\circ} \mathrm{C}$ in 2002, while daily maximum air temperature was $24.5^{\circ} \mathrm{C}$ in $1998,27.4^{\circ} \mathrm{C}$ in $1999,27.0^{\circ} \mathrm{C}$ in 2001 and $26.9^{\circ} \mathrm{C}$ in 2002 . Air temperature during the preharvest period apparently does not affect the rate of soluble solids accumulation (Reuther, 1973). Preharvest air temperature has a strong impact on the rate of decline in citric acid (Kurihara, 1969); however, we found no clear relationship between preharvest air temperature and acid content. Daily air temperature from 1 Sept. through 19 Nov. averaged $22.9^{\circ} \mathrm{C}$ in $1998,21.4^{\circ} \mathrm{C}$ in $1999,21.1^{\circ} \mathrm{C}$ in 2001 and $23.5^{\circ} \mathrm{C}$ in 2002.

Crop load has been reported to affect fruit quality (Harty and Sutton, 1994; Zheping et al., 2001). The lack of a difference in soluble solids and titratable acidity among years was somewhat surprising considering the large differences in cropload especially during the last 2 years (Fig. 2). Fully mature Satsuma mandarins have a natural tendency to bear biennially (Monselise and Goldschmidt, 1982). Even though the trees exhibited biennial bearing the last 2 years, the cropload was apparently not extreme enough to have a strong impact on soluble solids (Iguchi, 1980; Zheping et al., 2001).

Fruit weight varied by year, but there was no significant date $\times$ year interaction (Fig. 3). The difference between years was at least partially related to the cropload. The difference in fruit size did not affect soluble solids, titratable acidity or their ratio. In some studies, soluble solids differed with fruit weight (Kihara et al., 1981) whereas in others it did not (Iguchi, 1980). The conditions that would cause differences are not clear. The increase in fruit weight during the sampling period was due to an increase in fruit length. Fruit width did not differ among years nor was there a significant interaction between date and year. The length to diameter ratio also increased across dates and differed between the two years. The change in length to diameter ratio was due to change in fruit length, since width did not change.

Hue angle decreased as peel color progressed from green to yellow to orange (Fig. 4). On 10 Nov., hue angle was $\approx 80^{\circ}$, which was mostly yellow color but towards the orange rather than the green side of the spectrum. The fruit did not color uniformly such that even on the last sampling date, there were still some patches of green on the peel. Results of a recently conducted consumer preference survey of fruit from this region demonstrated that yellow-orange to orange was the preferred peel color (Campbell, 2003). Any green color in the peel strongly reduced preference by consumers not familiar with this fruit. These results indicated that those fruit that reach the

Fig. 2. Satsuma mandarin fruit yield from the third year after planting. The bars represent $2 x$ the standard error of the mean. The low yield in 1996 was due to a winter freeze.

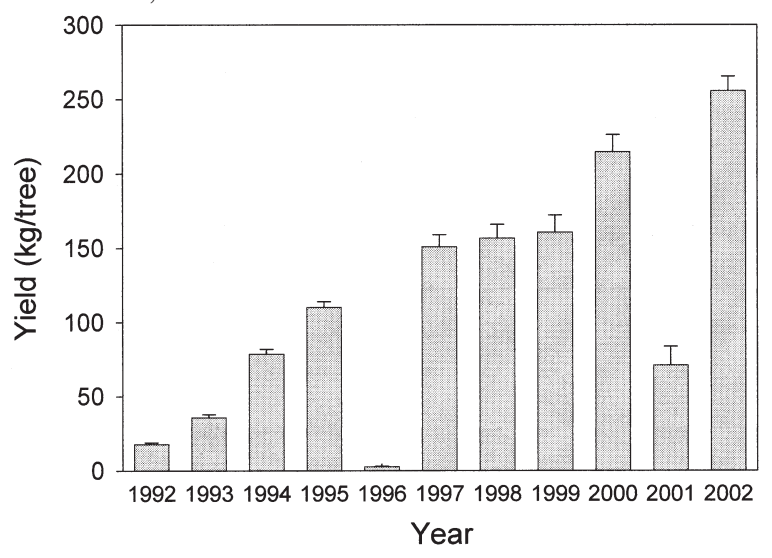



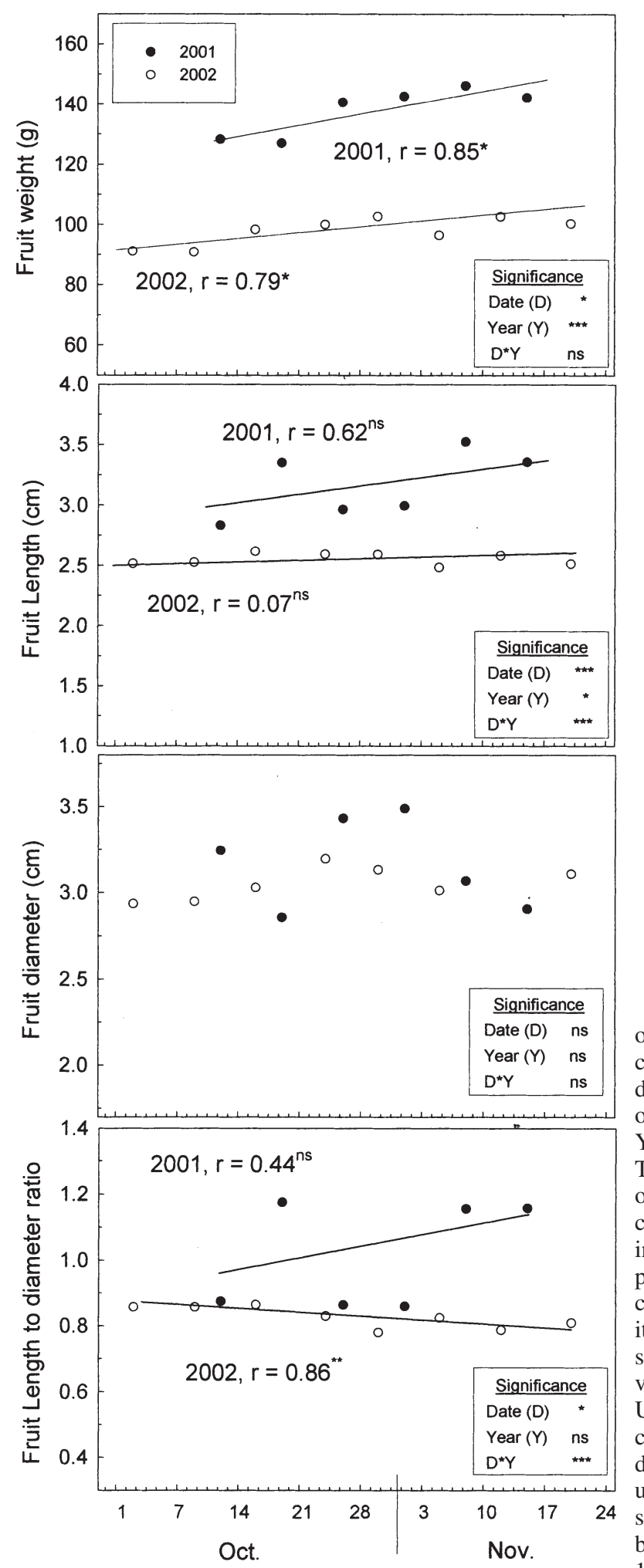

Fig. 3. Change in fruit weight, length, diameter and their ratio. ${ }^{* * *, * * * *}$ Significance levels in the analysis of variance were determined at $P \leq 0.05,0.01$, or 0.001 , respectively.

optimum internal quality of a 10:1 soluble solids to titratable acidity ratio would need degreening for optimum success in retail chain stores. Degreening with ethylene is a commonly used procedure for citrus (Grierson et al., 1986).

Preharvest air temperature affects devel-

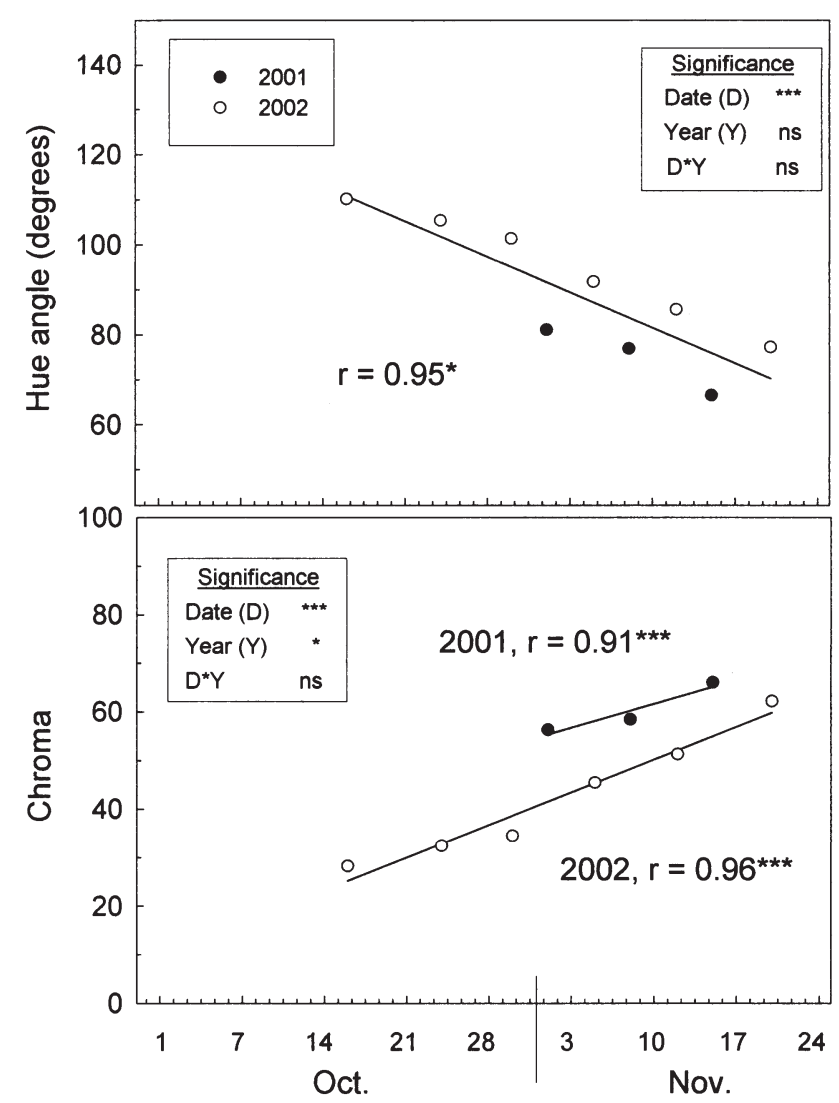

Fig. 4. Peel color up to and at the beginning of the early harvest period. Hue angle indicates the shift in color from green $\left(\approx 160^{\circ}\right)$ to yellow $\left(90^{\circ}\right)$ to orange $\left(45^{\circ}\right)$. Chroma is a measure of color intensity with $0=$ dull and $100=$ vivid. ${ }^{* * * * * * * *}$ Significance levels in the analysis of variance were determined at $P \leq 0.05,0.01$, or 0.001 , respectively.

opment of peel color, with cooler climates promoting development of yellow and orange color (Reuther, 1973; Young and Erickson, 1961). The effect of air temperature on titratable acidity and peel color but not on soluble solids indicates that development of peel color does not necessarily coincide with internal quality (Spiegel-Roy and Goldschmidt, 1996). Temperature variability in the southeastern U.S. causes variability in peel color among years, but natural degreening was not complete until December during this study. Because of the large gap between the average date the 10:1 soluble solids to titratable acidity ratio occurred (10 Nov.) and the typical time period that fruit naturally degreen completely (December), fruit would have to be degreened every year to satisfy consumer preferences in retail markets.

This study determined the earliest harvest date for Satsuma mandarins grown in the Southeast based on a 10:1 ratio of soluble solids to titratable acidity to be 10 Nov. The high quality fruit as measured by high soluble solids and titratable acidity contents and the fact that the 10:1 ratio occurred every year should make Satsuma mandarins grown in this region a highly competitive product in retail stores. However, based on the high degree of variability in soluble solids and titratable acidity values, a procedure will have to be developed to accurately sample commercial groves (Barry et al., 2003) to determine the date of reaching the 10:1 ratio. Since peel color still had green patches when the 10:1 ratio was reached, fruit will have to be degreened to satisfy consumer's preference (Campbell, 2003) or harvest delayed considerably. The cultivar used in this study, 'Owari', is a late-maturing cultivar. Use of earlier maturing cultivars (Bourgeois et al., 2002a, 2002b; Dawes and Martin, 1989) should provide a greater advantage in developing the early market; however, such cultivars must be evaluated in this climate to determine how flavor components and peel color react to temperature.

\section{Literature Cited}

Aharoni, Y. 1968. Respiration of oranges and grapefruit harvested at different stages of development. Plant Physiol. 43:99-102.

Barry, W., S. Castle, F. Davies, and R. Little. 2003. Variability in juice quality of 'Valencia' sweet orange and sample size estimation for juice quality. J. Amer. Soc. Hort. Sci. 128:803-808.

Bourgeois, W.J., R.J. Constantin, and M.J. Falcon. 2002a. 'Early St. Ann': A new early maturing Satsuma mandarin. HortScience 37:995-996. Bourgeois, W.J., R.J. Constantin, and M.J. Falcon. 
2002b. 'LA Early': A new early marketing Satsuma mandarin. HortScience 37:997-998.

Campbell, B. 2003. Consumer preferences for external Satsuma attributes. MS thesis. Auburn Univ., Auburn, Ala.

Dawes, S.N. and P.J. Martin. 1989. Early maturing Satsuma mandarins show promise. Orchardist N.Z. 62:11-12.

Eaks, I.L. 1970. Respiratory response, ethylene production, and response to ethylene of citrus fruit during ontogeny. Plant Physiol. 45:334-338.

Edling, R.J., R.J. Constantin, and W.J. Bourgeois. 1992. Louisiana citrus frost protection with enclosures and microsprinklers. Agr. For. Meteorol. 60:101-110.

Goldschmidt, E.E., M. Huberman, and R. Goren. 1993. Probing the role of endogenous ethylene in the degreening of citrus fruit with ethylene antagonists. Plant Growth Regulat. 12:325-329.

Grierson, W., E. Cohen, and H. Kitagawa. 1986. Degreening, p. 253-274. In: W.F. Wardoski, S. Nagy and W. Grierson (eds.). Fresh citrus fruit. AVI Publ. Co., Westport, Conn.

Halpern, D. and A. Zur. 1988. Total soluble solids in citrus varieties harvested at various stages of ripening, p. 1777-1783. In: R. Goren and K. Mendel (eds.). Proc. 6th Intl. Citrus Congr., Philadelphia-Rehovot. vol. 4. Balaban Publ., Weikersheim, Germany.

Harty, A.R. and P.G. Sutton. 1994. Crop regulation of Satsuma mandarin in New Zealand,p. $729-734.7^{\text {th }}$ Intl. Citrus Congr., Acireale, Italy, 8-13 Mar.

Iguchi, E. 1980. Studies on the improvement of fruit bearing in the Satsuma cv. Aoshima Unshu. I. The tendency towards alternate bearing and the relation between fruit quality and tree and orchard conditions. Shizuoka-Ken Kankitsu Shikenjo Kenkyu Hokoku 16:1-11.

Kihara, T., Y. Iba, and M. Nishiura. 1981. Fruit quality variation of Satsumas in relation to bearing situation, rind colour and fruit size. Bul. Fruit Tree Res. Sta., Okitsu, Japan.

Kurihara, A. 1969. Fruit growth of Satsuma orange under controlled condition. I. Effects of preharvest temperature on fruit growth, color development, and fruit quality in satsuma orange. Bul. Hort. Res. Sta. Japan (Ser. A)8:15-30.

Marsh, K.B., A.C. Richardson, and E.A. Macrae. 1999. Early- and mid-season temperature effects on the growth and composition of satsuma mandarins. J. Hort. Sci. Biotechnol. 74:443-451.

McAneney, K.J., A.C. Richardson, M.S. Astill, and P.A. Anderson. 1995. The inscrutable mandarin. Agr. For. Meteorol. 75:71-84.

McGuire, R.G. 1992. Reporting of objective color measurements. HortScience 27:1254-1255.

Monselise, S.P. 1986. Citrus, p. 87-108. In: S.P. Monselise (ed.). Handbook of fruit set and development. CRC Press, Boca Raton, Fla.

Monselise, S.P. and E.E. Goldschmidt. 1982. Alternate bearing in fruit trees, p. 128-173. In: J. Janick (ed.). Horticulture reviews. vol. 4. AVI Publ. Co., Westport, Conn.

Nesbitt, M., R.C. Ebel, R. McDaniel, W.A. Dozier, and D.G. Himelrick. 2000. Performance of Satsuma mandarin protected from freezing temperatures by microsprinkler irrigation. HortScience 35:856-859.

Reuther, W. 1973. Climate and citrus behavior, p. 280-337. In: W. Reuther (ed.). The citrus industry. 2nd ed. vol. 3. Univ. Calif. Press, Berkeley.

Richardson, A.C., K.B. Marsh, and E.A. Macrae. 1997. Temperature effects on satsuma mandarin fruit development. J. Hort. Sci. 72:919-929.

Rucker, B. R. 1996. Satsumaland! A history of citrus culture in West Florida. Gulf Coast Historical Rev. (Fall):62-75.

SAS Institute Inc. 1985. SAS/STAT guide for personal computers. V. 6. SAS Inst. Inc., Cary, N.C.

Spiegel-Roy, P. and E.E. Goldschmidt. 1996. Biology of citrus. Cambridge Univ. Press, Cambridge, U.K.

Vosbury, E.D. 1923. Culture of citrus fruit in the gulf states. USDA Farmers' Bul. 1343.

Voss, D.H and T.R. Robinson. 1992. Relating colorimeter measurement of plant color to the Royal Horticultural Society Colour Chart. HortScience 27:1256-1260.

Winberg, O.F.E. 1948. The Satsuma. Fairhope Courier (November).

Yelenosky, G. 1985. Cold hardiness in citrus, p. 201-238. In: J. Janick (ed.). Horticulture reviews. vol. 7. AVI Publ. Co., Inc. Westport, Conn.

Young, L.B. and L.C. Erickson. 1961. Influence of temperature on color change in Valencia oranges. Proc. Amer. Soc. Hort. Sci. 78:197-200.

Zhang, C., M. Nesbitt, F. Dane, and B. Ebel. 2002. Cold hardiness and genetic relationships among Satsuma mandarin cultivars, p. 504-505. XXVIth Intl. Hort. Congr. Exhibition, Orlando, Fla.

Zheping, M., J. Huang, and J. Xu. 2001. Investigation of the differences in fruit quality on different fruiting branches of early Satsuma mandarin varieties. South China Fruit 30:21. 